\title{
THE EFFECT OF ISOLATED SOY PROTEIN ON PLASMA BIOMARKERS IN ELDERLY MEN WITH ELEVATED SERUM PROSTATE SPECIFIC ANTIGEN
}

\author{
D. URBAN, W. IRWIN, M. KIRK, M. A. MARKIEWICZ, R. MYERS, M. SMITH, H. WEISS, \\ W. E. GRIZZLE AND S. BARNES
}

\begin{abstract}
From the Division of Urology, Departments of Surgery, Pathology and Pharmacology and Toxicology, and Biostatistics Unit and Mass Spectrometry Shared Facility, Comprehensive Cancer Center, University of Alabama at Birmingham and Pharmacy Department, University of Alabama Hospital, Birmingham, Alabama
\end{abstract}

\section{ABSTRACT}

Purpose: We performed a randomized double-blind crossover pilot study in elderly men with elevated prostate specific antigen (PSA) on the effects of the daily consumption of 2 soy beverages, each containing $20 \mathrm{gm}$. of isolated soy protein, on the isoflavone concentration in blood and urine, and on the 3 serum biomarkers cholesterol, PSA and the soluble p105 component of the p185erbB-2 proto-oncogene.

Materials and Methods: A total of 34 men supplemented their diet by consuming 1 of 2 soy protein beverages assigned randomly twice daily for a 6 -week period. In a second 6 -week period they consumed the other soy protein beverage. The beverage ISP+ provided $42 \mathrm{mg}$. of genistein and $27 \mathrm{mg}$. of daidzein daily, whereas the other beverage, ISP-, provided only 2.1 and $1.3 \mathrm{mg}$. of these isoflavones daily, respectively. Blood and 24-hour urine samples were obtained before the study, at 2 -week intervals during the study and 2 weeks after study completion.

Results: ISP + and to a lesser extent ISP - substantially increased the serum concentration and urinary output of the isoflavones and their metabolites. Serum cholesterol was significantly decreased by ISP + irrespective of the order in which the 2 soy beverages were administered and in apparent correlation with the total isoflavone concentration. There was no significant effect of the soy beverages on serum PSA and p105erbB-2 values.

Conclusions: This study reveals that short-term exposure of elderly men with elevated serum PSA values to soy protein containing isoflavones decreases serum cholesterol but not the serum biomarkers PSA and p105erbB-2.

KEY WORDS: prostate, prostate-specific antigen, soy proteins, biological markers, isoflavones

Carcinoma of the prostate is a major health problem in American men. In 1998 there were more than 184,500 newly diagnosed cases and more than 39,000 deaths. ${ }^{1}$ Because there is no curative therapy for advanced prostate cancer, recent interest has focused on prostate cancer prevention. Several lines of evidence imply that dietary alterations in American men may decrease the risk for and incidence of prostate cancer. While it has been speculated that a diet with less than $30 \%$ fat may result in a decreased risk of prostate cancer, others believe that compliance with such a low fat diet would be poor. Other epidemiological studies indicate that the level of dietary soy consumption may be linked to a decreased risk of prostate cancer. ${ }^{2,3}$ Soy contains large quantities of the isoflavone genistein (5,7,4í-trihydroxyisoflavone), a compound that is not present in other parts of the American diet (fig. 1). ${ }^{4}$ Men in southeast Asia, who consume 20 to 50 -fold more soy daily than American men, have a 10-fold lower incidence of clinically significant prostate cancer and prostate cancer related death. ${ }^{5,6}$ Thus, it has been hypothesized that American men may decrease the risk of prostate

Accepted for publication July 13, 2000.

Supported in part by a grant from the United Soybean Board. The mass spectrometer was purchased by funds from National Institutes of Health Instrumentation Grant S10RR06487 and from our institution. Operation of the University of Alabama at Birmingham Comprehensive Cancer Center Mass Spectrometry Shared Facility has been supported in part by National Cancer Institute Core Research Support Grant P30 CA13148 to the University of Alabama at Birmingham Comprehensive Cancer Center.

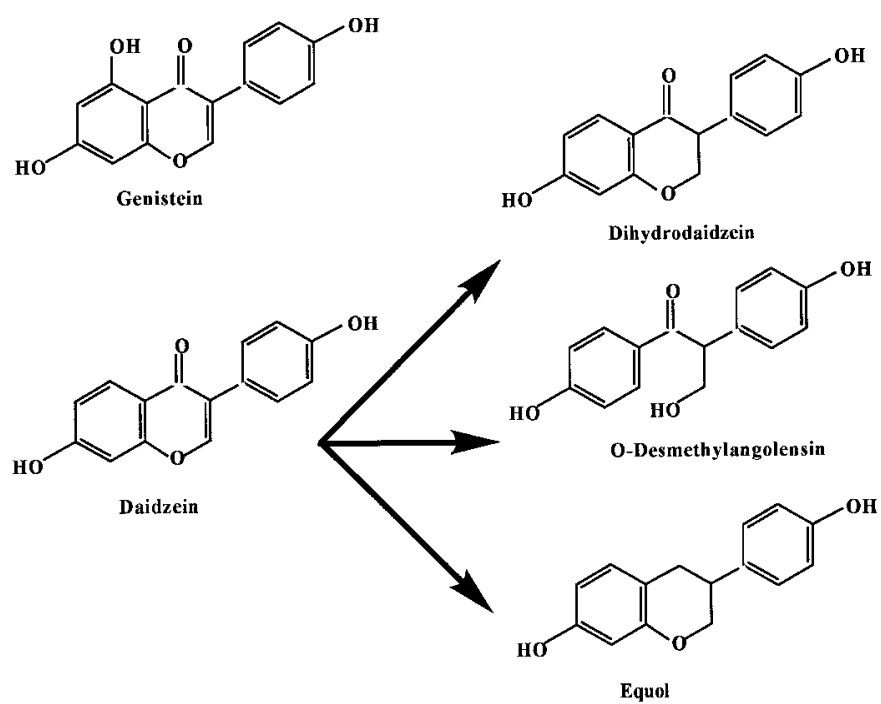

FIG. 1. Chemical structures of soy isoflavones and their metabolites measured in this study.

cancer by altering their diet to consume a higher level of soy proteins and, hence, genistein. ${ }^{6}$

Evidence that genistein is capable of inhibiting the human prostate growth was provided by a recent study on the histoculture of minced, surgically resected prostate tissue from 
men with benign prostatic hyperplasia. ${ }^{7}$ In this model 2 to 4 $\mu \mathrm{M}$. of genistein caused a $50 \%$ inhibition of DNA synthesis. It has also been shown that genistein not only inhibits the growth of rat prostate adenocarcinoma cells in culture $(22$ $\mu \mathrm{M} . \mathrm{IC}_{50}$ ), but also subcutaneously administered genistein inhibits the growth of rat adenocarcinoma cells injected in the flanks of Lobund-Wistar rats. ${ }^{8}$ Soy protein also decreases the number of prostatic tumors induced by testosterone in this susceptible rat strain. ${ }^{9}$ Furthermore, genistein administered in the diet, comprising up to $1 \mathrm{mg}$./gm. of AIN$76 \mathrm{~A}$, of Lobund-Wistar rats inhibited the growth of dorsolateral and ventral prostate tissue but had no effect on the size of the testes or liver. ${ }^{8}$ In contrast to genistein, the other major soy isoflavone daidzein (4í,7-dihydroxy-isoflavone) is weakly inhibitory for tumor cell growth in vitro (fig. 1). It had no inhibitory effect on the growth of DU-145 or LNCaP cells, in which growth was stimulated by serum or epidermal growth factor transforming growth factor- $\alpha{ }^{10}$

We performed a randomized double-blind crossover $2 \times$ 6-week trial of soy protein in elderly men without histologically confirmed prostatic cancer who presented with elevated serum prostatic specific antigen (PSA) of $4 \mathrm{ng} . / \mathrm{ml}$. or greater. The soy protein beverage ISP + used as the source of isoflavones was compared with the control soy protein preparation ISP-, which had been extracted with aqueous ethanol to decrease substantially isoflavones and other soluble components. We monitored the effect of the soy protein on the 2 serum biomarkers PSA and the soluble p105 component of the p185erbB-2 proto-oncogene as well as on serum total cholesterol. The latter was examined since morbidity in this patient group was more likely to be due to coronary heart disease and cardiovascular disease than prostatic cancer.

\section{MATERIALS AND METHODS}

Materials. 4-Methylumbelliferone, 4-methylumbelliferone sulfate, phenolphthalein, phenolphthalein glucuronide, Sephadex LH-20 and $\beta$-glucuronidase-sulfatase (type H-1 from Helix pomatia) were used. Solvents and other chemicals were high performance liquid chromatography grade or the best grade available. Brownlee Aquapore C8 reversed phase high performance liquid chromatography columns were obtained. Genistein was recovered and purified from soy molasses, as previously described..$^{10} \mathrm{O}$-desmethylangolensin, dihydrodaidzein, equol standards, daidzein and biochanin $\mathrm{A}$ were obtained.

Two forms of the isolated soy protein based beverage were used in this study. ISP+ was prepared by conventional commercial methods, thus, preserving its usual complement of soy phytochemicals. It contained 42 and $27 \mathrm{mg}$. of genistein and daidzein conjugates, respectively, as determined by reverse phase high performance liquid chromatography. ${ }^{11}$ ISP - was prepared by the exhaustive extraction of ISP+ with hot ethanol, thereby, removing $95 \%$ of it isoflavones as well as other soluble phytochemicals. It contained 2.1 and 1.3 $\mathrm{mg}$. of genistein and daidzein conjugates, respectively. The beverages were formulated per serving with ISP + or ISP(18.76 gm.), sucrose, fructose, maltodextrin, aspartame, the minerals calcium pantothenate $(601 \mathrm{mg}$.), dimagnesium phosphate (55 mg.), zinc oxide (2.41 mg.), vitamins A (1,060 IU), B1 (0.131 mg.), B2 (0.448 mg.), B6 (0.217 mg.), B12 (2.34 $\mu \mathrm{g}$.), C (2.7 mg.) D (132 IU) and folacin (74 $\mu \mathrm{g}$.), and $102 \mathrm{kCal}$. The beverages were prepared as a dry powder and placed in sachets with 1 sachet used for each serving.

Our study included 34 men older than 55 years with a serum PSA at presentation of greater than $4 \mathrm{ng} . / \mathrm{ml}$. The sample size requirement of 17 patients per arm was based on testing the null hypothesis that the proportion of subjects with a response on the biomarker would be equal to $25 \%$ of the ISP - versus $50 \%$ of the ISP+ group with $5 \% \alpha, 80 \%$ power and a correlation of 0.20 among the 8 repeat measurements resulting from the crossover study design. None of the men had histologically confirmed prostate cancer, in 17 a pre-study prostate biopsy had shown no cancer and the remainder had elected not to undergo biopsy for elevated PSA. All participants were free of gastrointestinal and heart disease, and were not being treated with antibiotics or androgen ablation therapy. Table 1 shows patient demographics.

At the first visit at study entry a fasting blood sample and urine specimen were obtained. Subjects were then randomly assigned to a 6 -week period of consuming 1 of the 2 soy beverages. A computer generated randomization scheme using a block size of 4 was prepared by the study statistician. The treatment and randomization list was provided to the study pharmacist, who in turn was responsible for preparing the treatment in a blinded fashion with study labels and patient identification numbers. Only the statistician and pharmacist were aware of the type of soy beverage that each patient consumed during the study.

Subjects were examined every 2 weeks at weeks 2,4 and 6 with fasting blood and 24-hour urine samples obtained at each visit. At the 6 -week visit subjects were changed to the other soy beverage for a further 6 weeks and were again examined every 2 weeks at weeks 8,10 and 12 with fasting blood and 24-hour urine specimens obtained. During the last 2 study weeks at weeks 12 to 14 subjects consumed no soy beverages. At the last visit at week 14 fasting blood and 24-hour urine samples were obtained. Urine specimens were stored at $4 \mathrm{C}$ during each collection period. At the clinic total urine volume was noted and $2,25 \mathrm{ml}$. aliquots were stored at $-80 \mathrm{C}$ until analyzed for the phytoestrogen content. After separation by centrifugation serum samples were also stored at $-80 \mathrm{C}$.

Subjects were instructed to mix the soy beverage material with 8 ounces of fluid, such as water, fruit juice or carbonated drink, and consume the contents of 2 sachets daily, including 1 in the morning and the other in the afternoon or evening. They were given sufficient sachets for each 2-week period between clinic visits. They maintained a daily record of when they consumed the beverages and returned all unused sachets at each clinic visit, which enabled the pharmacist to determine the number of sachets used.

Assays of blood biomarkers. Serum PSA was measured using the Abbott AXSYM* PSA assay. ${ }^{12}$ Serum p105erbB-2 was determined using a quantitative enzyme immunoassay. ${ }^{13}$ The assay sandwich enzyme-linked immunosorbent assay used a mouse monoclonal antibody immobilized to the surface of microplate wells for capture and rabbit polyclonal antiserum to detect human p185erbB-2. Each antibody recognizes the $105 \mathrm{kDa}$. extracellular portion of p185erbB-2.

* Abbott Laboratories, Abbott Park, Illinois.

TABle 1. Patient demographic characteristics

\begin{tabular}{|c|c|c|c|}
\hline Variable & $\mathrm{ISP}^{-}$to $\mathrm{ISP}^{+}$ & $\mathrm{ISP}^{+}$to $\mathrm{ISP}^{-}$ & Totals \\
\hline \multicolumn{4}{|l|}{ No. race $(\%)$ : } \\
\hline White & $13 \quad(76)$ & $12 \quad(71)$ & (74) \\
\hline Black & (24) & $4 \quad(23)$ & (24) \\
\hline Other & 0 & (6) & (2) \\
\hline Mean age \pm SEM (median) & $67.9 \pm 1.6$ & $62.8 \pm 4.3 \quad(67.1)$ & $65.3 \pm 2.3 \quad(67.1)$ \\
\hline Mean pounds wt. \pm SEM (median) & $183.4 \pm 7.4(174.5)$ & $209.6 \pm 7.3(214.7)$ & $196.5 \pm 5.6(181.8)$ \\
\hline
\end{tabular}


The rabbit antibody was measured by adding an antirabbit IgG-horseradish peroxidase conjugate that catalyzes the conversion of o-phenylenediamine into a colored product. The standards supplied with the kit were calibrated in arbitrary human Neu units per ml. as well as in fmol./ml. ${ }^{13}$

Serum total cholesterol was determined on a Beckman Synchrom LX $\dagger$ system using a timed end-end point method. ${ }^{12}$ In the reaction cholesterol esters are hydrolyzed to free cholesterol and fatty acids. Free cholesterol is oxidized to cholesten-3-1 and hydrogen peroxide by cholesterol oxidase. Peroxidase catalyzes the reaction of hydrogen peroxide with 4-aminoantipyrine and phenol to produce a colored quinoneimine product. The system automatically proportions the samples (1 volume) and reagent (100 volumes) into the cuvette. Absorbance at $520 \mathrm{~nm}$. is monitored. The change is directly proportional to the concentration of cholesterol in the sample, which is automatically calculated by the system.

Analysis of isoflavones. The isoflavone content of the beverages used in this study was determined by reversed phase high performance liquid chromatography ${ }^{11}$ with results expressed in $\mathrm{mg}$./gm. of aglucons. Concentration of the soy isoflavones and their metabolites in serum and urine was determined as previously described. ${ }^{14,15}$ Briefly, $1 \mathrm{ml}$. aliquots of serum and urine were mixed with the internal standards phenolphthalein glucuronide, 4-methylumbelliferone sulfate and biochanin A. The $\mathrm{pH}$ was adjusted to 5 by adding $250 \mu \mathrm{l}$. of $1 \mathrm{M}$. ammonium acetate buffer. $\beta$-Glucuronidase-sulfatase (363 units of $\beta$-glucuronidase and 15 to 40 units of sulfatase) was added and the samples were incubated at $37 \mathrm{C}$ overnight. The aglucons of the isoflavones and their metabolites were recovered by diethyl ether extraction after adding $100 \mu \mathrm{l}$. glacial acetic acid. For serum this mixture was extracted with 3 volumes of $n$-hexane to remove most of the fat content and then 3 times with $2 \mathrm{ml}$. of diethyl ether to recover the aglucons of the isoflavones and their metabolites. For urine the n-hexane step was not used. The diethyl ether extracts were combined, evaporated to dryness under nitrogen at room temperature and redissolved in $80 \%$ aqueous methanol $(100 \mu \mathrm{l}$. and $500 \mu \mathrm{l}$. for plasma and urine extracts, respectively) before high performance liquid chromatography-mass spectrometry analysis.

High performance liquid chromatography-mass spectrometry of plasma isoflavones. High performance liquid chromatography was performed on a $10 \mathrm{~cm}$. $\times 4.6 \mathrm{~mm}$. internal diameter, 300 A. pore size, Aquapore C8 reversed phase high performance liquid chromatography column. Isocratic conditions was used ( $30 \%$ acetonitrile in $10 \mathrm{mM}$. ammonium acetate, pH 7) at a flow rate of $1 \mathrm{ml}$. per minute. Serum $(20 \mu \mathrm{l}$.) or urine $(5 \mu \mathrm{l}$.) extracts were injected onto the chromatography column. After chromatographic separation the eluate stream was diluted with $13 \mu \mathrm{l}$. per minute of ammonium hydroxide provided by a Harvard infusion pump and passed into the HN-APCI interface. The orifice potential of the mass spectrometer was set at $-60 \mathrm{~V}$. Multiple reaction ion monitoring was done by selecting specific isoflavonoid parent molecular ions in the first quadrupole and after collision with neutral gas by measuring specific daughter ions in the third quadrupole. ${ }^{11,14,15}$

Statistical analysis. Descriptive statistics were calculated for serum isoflavonoids, PSA, cholesterol and p105erbB-2 levels for the first and second study periods. To adjust for baseline measurements the change from baseline to the first and second periods was calculated. For serum isoflavonoid outcomes baseline values were subtracted from the first and second period measurements, while the first and second period measurements were subtracted from the baseline values of the cholesterol, PSA and p105erbB-2 outcomes. We compared the ISP + and ISP - groups by calculating the difference in the change from baseline between the first and second periods. We then compared this difference in subjects

$\dagger$ Beckman Instruments, Inc., Palo Alto, California. who received ISP - in the first period and crossed over to ISP + in the second period versus those who received treatment in the reverse order. The Wilcoxon rank sum nonparametric test ${ }^{16}$ was done to compare changes from baseline to outcome in the ISP+ and ISP - groups.

The Wilcoxon signed ranks test was also done to evaluate further any significant changes from baseline in cholesterol, PSA and erbB-2. Longitudinal data analysis was performed to determine the stability of erbB-2 measurements with time. Furthermore, we evaluated the correlation of changes in cholesterol with the serum isoflavone concentration by calculating Spearman's correlation coefficient with significance testing done to determine whether this correlation was significant.

Normality assumptions were tested for each isoflavone and biomarker outcome. The appropriate nonparametric procedures as described were used for outcomes that violated the normality assumptions. All analysis was performed using a commercially available software package.

\section{RESULTS}

Accrual of the planned 34 subjects was completed 11 months after the first subject was enrolled. Subjects sustained isolated soy protein diet supplementation for 2,6 -week periods. No statistically significant adverse events were reported by study participants. Constipation was the most frequently reported adverse event in 6 of 17 (35\%) ISP - to ISP+ and in 2 of 17 $(12 \%)$ ISP + to ISP - subjects $(\mathrm{p}=0.22)$. Diarrhea or loose stool was noticed by 2 of $17(12 \%)$ ISP - to ISP + and 1 of $17(6 \%)$ ISP + to ISP - subjects, while bronchial irritation was noticed by 1 of 17 (6\%) in each group. No participant discontinued the study packets or withdrew from study because of these adverse events. Two subjects withdrew from study, including 1 due to employment and the other due to unrelated surgery. Compliance in consuming the beverages based on packet count and interview was excellent in 31 of the 32 remaining subjects. However, chromatography-mass spectrometry revealed that 3 other subjects were consuming a diet that contained substantial amounts of soy. Thus, statistical analysis was done in the remaining 28 subjects divided into ISP + to ISP - and ISP - to $\mathrm{ISP}+$ groups.

Effects on serum isoflavonoids. In the subjects who received ISP - in the first period and crossed over to ISP + in the second period mean serum genistein was 110 (median 97) and $955 \mathrm{nM}$. (median 713) for the first and second periods, respectively (table 2 ). On the other hand, in those who received ISP + followed by ISP - mean serum genistein was 573 (median 601) and $77 \mathrm{nM}$. (median 76), respectively. The change in serum genistein from baseline to period 1 as well as from baseline to period 2 was also calculated. The difference in the changes from baseline was calculated from periods 1 to 2 and compared in participants who first received ISP - and then ISP + versus those who received treatment in the reverse order. There was a statistically significant difference in serum genistein concentration in the 2 groups (Wilcoxon rank sum $\mathrm{p}<0.001$ ). Specifically the serum concentration significantly increased from baseline in the ISP+ group compared with that in the ISP - group.

A similar trend was evident for the other isoflavones and their metabolites (table 2). Serum isoflavonoid concentrations were significantly higher in the ISP + than in the ISP - group. Likewise comparing the change from baseline in serum isoflavonoid concentration indicated a significant increase in the ISP + group compared with that in the ISP - group for all isoflavonoids except equol ( $\mathrm{p}<0.001$, table 2$)$.

Effects on serum PSA and erbB-2. Mean serum PSA was 8.7 (median 6.6) and $8.7 \mathrm{ng} . / \mathrm{ml}$. (median 5.8) in men who received ISP - and then ISP + in the first and second periods, respectively (table 3 ). In those who received ISP + followed by ISP- mean serum PSA was 7.8 (median 5) and $8.2 \mathrm{ng} . / \mathrm{ml}$. 
TABLE 2. Serum concentration of isoflavones and their metabolites in men consuming soy protein beverages at baseline, and at first and second periods of the study

\begin{tabular}{|c|c|c|c|c|c|c|c|}
\hline \multirow{2}{*}{ Phytoestrogen } & \multicolumn{3}{|c|}{$\mathrm{ISP}-$ to ISP+ } & \multicolumn{3}{|c|}{$\mathrm{ISP}+$ to ISP- } & \multirow{2}{*}{$\begin{array}{c}\mathrm{p} \text { Value* } \\
\text { (Wilcoxon rank sum test) }\end{array}$} \\
\hline & Mean & Median & Range & Mean & Median & Range & \\
\hline Genistein (nM.): & & & & & & & $<0.001$ \\
\hline Baseline & 23.2 & 17.1 & $6.28-88.52$ & 18.3 & 16.4 & $0-68.78$ & \\
\hline First period & 110.3 & 96.9 & $48.78-265.01$ & 573.1 & 600.8 & $127.42-1,337.78$ & \\
\hline Second period & 954.6 & 713.2 & $57.84-4,001.58$ & 76.7 & 76.3 & $26.86-131.73$ & \\
\hline Daidzein (nM.): & & & & & & & $<0.001$ \\
\hline Baseline & 19.3 & 17.0 & $0-49.76$ & 14.3 & 13.1 & $0-32.25$ & \\
\hline First period & 50.9 & 38.7 & $20.76-192.64$ & 227.6 & 225.9 & $16.75-479.88$ & \\
\hline Second period & 322.5 & 247.5 & 27.9-906.92 & 37.7 & 33.3 & $12.26-72.34$ & \\
\hline Dihydrodaidzen (nM.): & & & & & & & $<0.001$ \\
\hline Baseline & 6.1 & 4.0 & $0-32.0$ & 2.7 & 2.0 & $0-8.0$ & \\
\hline First period & 20.1 & 9.0 & $1.0-105.0$ & 49.4 & 44.0 & $2.0-153.0$ & \\
\hline Second period & 63.5 & 44.4 & $0.91-263.92$ & 7.3 & 6.1 & $0-27.06$ & \\
\hline Equol (nM.): & & & & & & & 0.109 \\
\hline Baseline & 7.3 & 1.1 & $0-71.21$ & 2.2 & 0 & $0-10.97$ & \\
\hline First period & 8.2 & 5.0 & $0-41.0$ & 51.1 & 2.0 & $0-335.0$ & \\
\hline Second period & 73.7 & 5.3 & $0-463.47$ & 6.8 & 4.7 & $0-32.49$ & \\
\hline O-desmethylangolensin (nM.): & & & & & & & $<0.001$ \\
\hline Baseline & 2.7 & 2.6 & $0-7.5$ & 2.1 & 1.2 & $0-10.86$ & \\
\hline First period & 8.1 & 7.4 & $1.66-28.53$ & 136.6 & 84.1 & $6.83-388.72$ & \\
\hline Second period & 88.3 & 44.6 & $1.84-330.39$ & 13.6 & 11.6 & 0-40.65 & \\
\hline
\end{tabular}

TABLE 3. Mean PSA, erbB-2 and serum total cholesterol at baseline, and at first and second periods of the study

\begin{tabular}{|c|c|c|c|c|c|}
\hline \multirow{2}{*}{ Biomarker } & \multicolumn{2}{|c|}{ ISP - to ISP+ } & \multicolumn{2}{|c|}{ ISP+ to ISP- } & \multirow{2}{*}{$\begin{array}{c}\mathrm{p} \text { Value* } \\
\text { (Wilcoxon rank sum test) }\end{array}$} \\
\hline & Mean & Median & Mean & Median & \\
\hline Mean cholesterol (mg./100 ml.): & & & & & 0.036 \\
\hline Baseline & 189.9 & 187.5 & 200.7 & 195.0 & \\
\hline Change from baseline & -5.0 & -8.0 & 14.7 & 17.5 & \\
\hline Second period & 181.9 & 182.5 & 186.8 & 190.0 & \\
\hline Change from baseline & 9.5 & 7.0 & 13.8 & 13.5 & \\
\hline Mean PSA (ng./ml.): & & & & & 0.622 \\
\hline Second period & 8.7 & 5.8 & 8.2 & 6.9 & \\
\hline Change from baseline & 0.45 & -0.10 & -0.68 & -0.65 & \\
\hline Mean erbB-2 (human Neu units/ml.): & & & & & 0.727 \\
\hline Baseline & 29.5 & 26.0 & 30.0 & 27.1 & \\
\hline First period & 29.9 & 27.6 & 28.8 & 27.6 & \\
\hline Change from baseline & -0.43 & -0.25 & 1.21 & 0.30 & \\
\hline Second period & 28.1 & 29.0 & 28.2 & 27.0 & \\
\hline
\end{tabular}

*Changes from baseline in ISP - and ISP+ groups.

(median 6.9), respectively. Comparing the change in serum PSA from baseline indicated no significant difference in either group ( $\mathrm{p}=0.622$, table 3$)$.

In participants who received ISP - and then crossed over to ISP + mean serum p105erbB-2 was 29.9 (median 27.6) and 28.1 human Neu units per ml. (median 29), respectively. On the other hand, mean erbB-2 was 28.8 (median 27.6) and 28.2 human Neu units per ml. (median 27) in those who received ISP + and then ISP - , respectively. Comparing the change in serum p105erbB-2 from baseline indicated no significant difference in the ISP + compared with the ISP - group $(\mathrm{p}=0.727$, table 3$)$.

Longitudinal analysis of p105erb2 data during the first 4 weeks in men who received ISP - indicated no significant change with time $(p=0.785)$. Similarly no significant change in p105erb2 was observed in those who received ISP + during the first 4 weeks $(p=0.604)$. A similar finding of stable p105erb2 was observed in the subsequent 4 weeks in participants who received ISP + and ISP- $(\mathrm{p}=0.288$ and 0.056 , respectively).

Effects on cholesterol. There was an evident decrease in plasma cholesterol during soy protein administration. Mean plasma cholesterol was 194.9 (median 198) and $181.9 \mathrm{mg} . /$ $100 \mathrm{ml}$. (median 182.5) in subjects who received ISP - and then ISP + , respectively (table 3 ), compared with a baseline concentration of $189.9 \mathrm{mg} . / 100 \mathrm{ml}$. (median 187.5). In those who received ISP + and then ISP - mean plasma cholesterol was 186 (median 178) and $186.8 \mathrm{mg} . / 100 \mathrm{ml}$. (median 190), respectively, compared with a baseline concentration of 200.7 $\mathrm{mg} . / 100 \mathrm{ml}$. (median 195). Comparing the change in plasma cholesterol from baseline indicated a statistically significant decrease in the ISP + compared with the ISP - group ( $\mathrm{p}<0.036$, table 3 ).

Using paired differences between pre-study and post-study values, and values at the end of each 6 -week study period men on ISP + in the first 6-week period had a significant 14.7 $\mathrm{mg} . / 100 \mathrm{ml}$. decrease in plasma cholesterol (Wilcoxon signed ranks $\mathrm{p}=0.001$ ), whereas those on ISP - had a nonsignificant $5 \mathrm{mg} . / 100 \mathrm{ml}$. increase ( $\mathrm{p}=0.385$, table 4 and fig. 2 ). When participants on ISP - in the first 6-week period crossed over to ISP + in the second 6-week period, plasma cholesterol

TABLE 4. Effect of isolated soy protein on within-patient variations in blood biomarkers

\begin{tabular}{cccc}
\hline \multirow{2}{*}{ Group } & \multicolumn{3}{c}{ Mean Mg./100 Ml. Cholesterol \pm SEM } \\
\cline { 2 - 4 } & Study 1-Pre-Study & Study 2-Study 1 & Off Study-Study 2 \\
\hline ISP+ to ISP- & $-14.6 \pm 3.6$ & $0.8 \pm 4.6$ & $6.1 \pm 3.0$ \\
ISP- to ISP+ & $5.0 \pm 4.6$ & $-13.0 \pm 4.2$ & $9.1 \pm 4.6$ \\
\hline
\end{tabular}


decreased significantly by $13 \mathrm{mg} . / 100 \mathrm{ml}$. Interestingly crossing over from ISP + to ISP - was associated with a minimal (0.8 mg./100 ml.) nonsignificant increase in plasma cholesterol (fig. 2). In each group plasma cholesterol significantly increased in the 2-week period after all isolated soy protein intake ceased (ISP + to ISP - $9.1 \mathrm{mg} . / 100 \mathrm{ml}$. and ISP - to ISP $+6.1 \mathrm{mg} . / 100 \mathrm{ml}$., fig. 2). In contrast to plasma cholesterol, neither form of isolated soy protein significantly affected serum PSA or p105erbB-2 irrespective of the order of administration (table 4).

Using the results of the first 6-week study period we determined the relationships of the change in serum cholesterol with serum isoflavonoid. In 39 samples from men consuming ISP + these factors significantly correlated negatively $(r=$ $-0.550, \mathrm{p}<0.05$ ), that is as serum isoflavonoid increased, serum cholesterol increasingly decreased (fig. 3). At the lower concentrations of isoflavonoids there was no cholesterol decreasing effect. Least square regression analysis estimated that the minimum serum isoflavonoid concentration causing a cholesterol decreasing effect was $266 \mathrm{nM}$. In 42 samples from subjects consuming ISP - there was no correlation of these factors $(r=0.024$, not significant). All but 5 samples examined in the ISP - group had an isoflavonoid concentration of less than $260 \mathrm{nM}$.

\section{DISCUSSION}

In a 6 -week study isoflavone containing soy protein beverages had no statistically significant effect on serum PSA or p105erbB-2. In contrast, a statistically significant decrease of 13 to $15 \mathrm{mg} . / 100 \mathrm{ml}$. in serum cholesterol was observed in these subjects when they consumed ISP + but not ISP - in the first study period. This latter effect is consistent with a large number of clinical studies on the role of soy proteins on blood lipid concentrations, as summarized by Anderson et al. ${ }^{17}$ The recent study of Crouse et al also showed that increasing the amount of isoflavones (range 3 to $62 \mathrm{mg}$. daily) in otherwise similar isolated soy protein preparations caused a dose related decrease in plasma cholesterol. ${ }^{18}$ Since the altered isoflavone dose would be expected to increase plasma isoflavones, it is reasonable to predict that the wide range in plasma isoflavones from a single dose due to the normal variation in uptake, metabolism and elimination would also correlate with decreased cholesterol. This result is important since elderly men diagnosed with prostate cancer are nevertheless more likely to die of coronary heart disease or cardiovascular disease than of cancer. In the Framingham study Tyroler reported that a $1 \%$ decrease in plasma cholesterol decreases the risk of cardiovascular death by $3 \% .{ }^{19}$ This effect of the soy protein beverage on blood cholesterol should be regarded as increasing longevity.

As expected, in all cases the serum concentration and urinary output of the isoflavones daidzein and genistein increased substantially when subjects consumed the ISP+ beverage compared with samples from the periods with no soy consumption at the start and end of the study (data not shown). Interestingly these values were also higher when subjects consumed the ISP - beverage. This finding correlates with the small amount of isoflavones remaining in ISP - after ethanol extraction. Thus, in this study the ISPbeverage was not a strict control for the ISP+ beverage. The amount of isoflavones in the ISP - beverage was considerably greater than in the majority of nonsoy foods and may have had a biological effect.

The correlation of the extent of the decrease in serum cholesterol while on ISP + with the increase in serum isoflavonoid concentration implies that isoflavones may have a causative role in decreasing cholesterol. Since in mice with defective low density lipoprotein receptors soy protein no longer has a cholesterol decreasing effect, ${ }^{20}$ isoflavonoids may act as estrogen analogues. This role of isoflavones has been disputed by others with some insisting that the soybean protein fraction is solely responsible for the cholesterol decreasing effects of soy foods. ${ }^{21,22}$ However, this scenario is also unlikely since in men on ISP - there was no cholesterol decreasing effect. A more complex explanation appears warranted because in subjects previously treated with ISP+
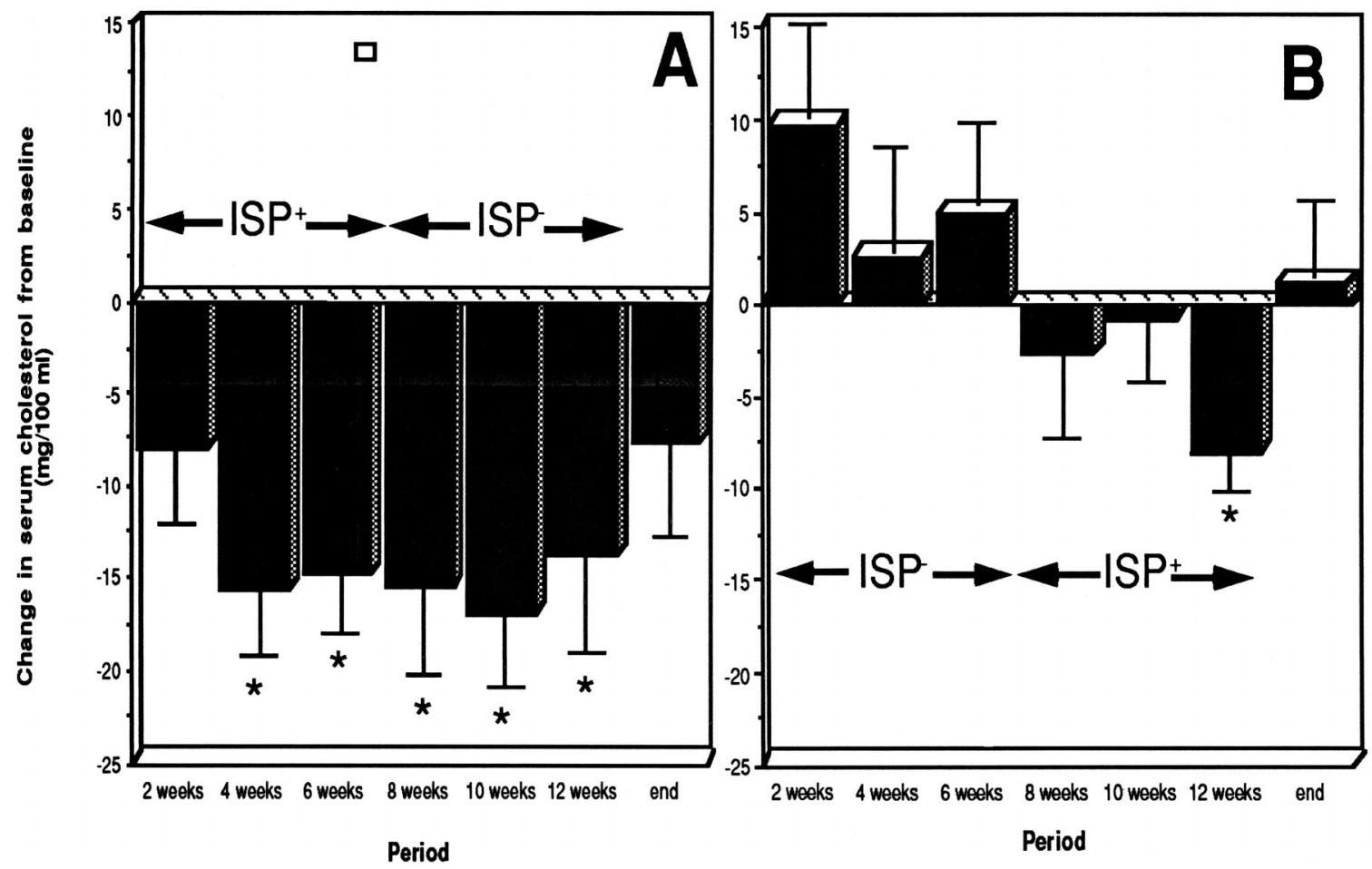

FiG. 2. Mean changes plus or minus standard error of mean in serum cholesterol concentration at 2-week intervals during 14-week study from pre-study values. $A$, ISP + in first 6 -week period and ISP - in second 6 -week period. $B$, ISP - in first 6 -week period and ISP + in second 6 -week period. Asterisk indicates significant difference from $0(\mathrm{p}>0.05)$. 


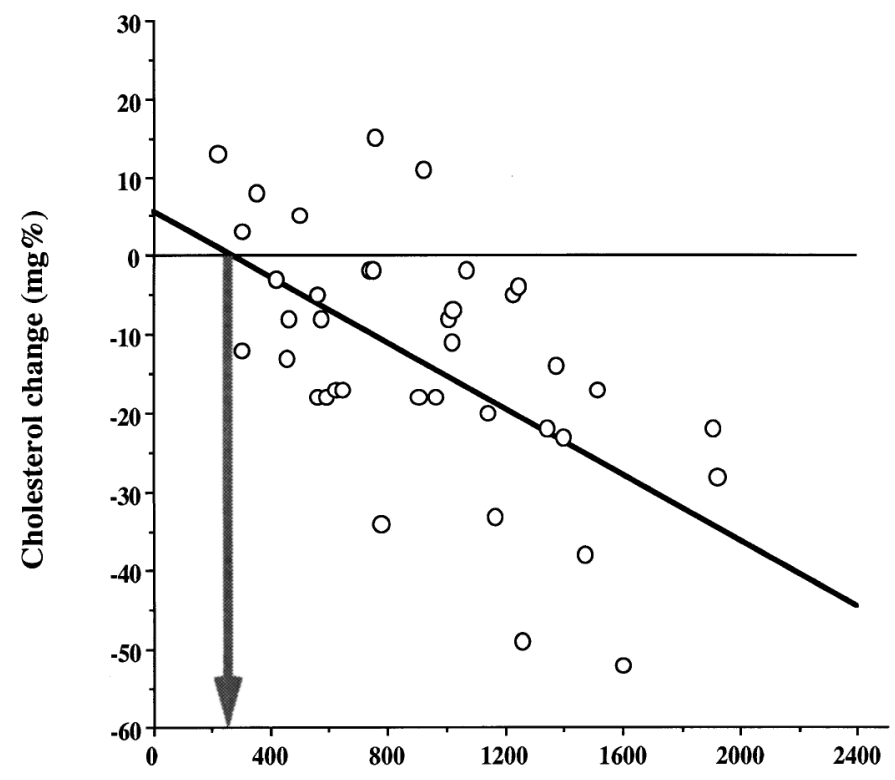

Isoflavone concentration (nM)

FIG. 3. Change in serum cholesterol and total serum isoflavonoids in 14 patients consuming ISP + in first 6 -week period. Data are significantly negatively correlated $(\mathrm{r}=-0.550, \mathrm{p}<0.05)$ and described by equation, change in cholesterol $=-0.01976 \times$ (isoflavone concentration) +5.255 . Using this equation predicted minimum serum isoflavone concentration required to obtain cholesterol lowering effect is $266 \mathrm{nM}$.

crossing over to ISP - did not lead to increased plasma cholesterol despite the decreased serum isoflavonoid concentration. Return of the serum cholesterol concentration to prestudy values was only observed when study participants completely stopped consuming isolated soy protein. This finding implies that the components in ISP + have a memory effect that lasts several weeks and, therefore, may interact with ISP - . A possible explanation is binding by soy proteins in the intestine of bile acids, the principal cholesterol metabolites. ${ }^{23}$ This effect is analogous to that of cholestyramine in interrupting the enterohepatic circulation of bile acids.

The lack of the response of serum PSA or p105erbB-2 in this pilot study may be due to several factors. It may be a function of participant selection and the number of subjects in this study. It is possible that a study with a greater number of subjects would confirm a statistically significant trend correlating PSA with ISP + beverage consumption. Selecting men in whom previous prostatic biopsy showed prostatic intraepithelial neoplasia without cancer may identify a group more likely to respond to ISP+.

While earlier series described differences in serum p105erbB-2 in patients with adenocarcinoma of the breast and prostate, to our knowledge little information is available on the temporal stability of p105erbB-2. Our study demonstrates that in relatively healthy older men p105erbB-2 remained constant during a 14 -week period. In addition, the dose of isoflavones that is effective for altering blood biomarkers, such as PSA and p105erbB-2, in a 6 -week period may be substantially higher than the dose provided by the soy protein beverage. In cell culture studies genistein decreased PSA production of human prostate carcinoma LNCaP cells but at a dose of $40 \mu \mathrm{M}$., which is 40 -fold the concentration in our study. ${ }^{24}$ A larger dose of partially purified isoflavones or a soy product containing a greater concentration of isoflavones may result in a more profound effect on these biomarkers. The growth of transplanted human prostate cancer LNCaP cells in SCID mice was inhibited $30 \%$ to $40 \%$ by adding a genistein containing ( $1 \%$ by weight) phytochemical extract of soy to their diet. ${ }^{25}$ Using methylated isoflavones from an extract of clover in a man with newly histologically diagnosed prostate cancer Stephens reported that $4 \times 40 \mathrm{mg}$. doses given daily led to extensive apoptosis in biopsies done at prostatectomy 1 week later. ${ }^{26}$ Furthermore, longer diet intervention is recommended for at least 6 or preferably 12 months to determine the effect of the soy protein beverages on these biomarkers. In addition, an alternative to the ISPused as a placebo beverage is needed since ISP - contributed significant amounts of isoflavones, increasing serum isoflavones as well as their urinary excretion and, thereby, confounding the study design.

O-desmethylangolensin, dihydrodaidzein and equol standards were provided by Dr. Kristiina Wähälä, Department of Chemistry, University of Helsinki, Finland, and isolated soy protein based beverage was supplied by Protein Technologies International, St. Louis, Missouri.

\section{REFERENCES}

1. Parker, S. L., Tong, T., Bolden, S. et al: Cancer statistics, 1996. CA Cancer J Clin, 65: 5, 1996

2. Severson, R. K., Nomura, A. M. Y., Grove, J. S. et al: A prospective study of demographics, diet and prostate cancer among men of Japanese ancestry in Hawaii. Cancer Res, 49: 1857, 1989

3. Oishi, K., Okada, K., Yoshida, O. et al: A case-control study of prostatic cancer with reference to dietary habits. Prostate, 12: 179,1988

4. Coward, L., Barnes, N. C., Setchell, K. D. R. et al: Genistein, daidzein, and their $\beta$-glycoside conjugates: antitumor isoflavones in soybean foods from American and Asian diets. J Agric Food Chem, 41: 1461, 1993

5. Stamey, T. A. and McNeal, J. E.: Adenocarcinoma of the prostate. In: Campbell's Urology, 6th ed. Edited by P. C. Walsh, A. B. Richie, T. A. Stamey et al. Philadelphia: W. B. Saunders, vol. 2, p. 1159,1992

6. Messina, M., Persky, V., Setchell, K. D. R. et al: Soy intake and cancer risk: a review of in vitro and in vivo data. Nutr Cancer, 21: 113,1994

7. Geller, J., Sionit, L., Partido, C. et al: Genistein inhibits the growth of human-patient BPH and prostate cancer in histoculture. Prostate, 34: 75, 1998

8. Dalu, A., Haskell, J. F., Coward, L. et al: Genistein, a component of soy, inhibits the expression of the EGF and ErbB/Neu receptors in the rat dorsolateral prostate. Prostate, 37: 36, 1998

9. Pollard, M. and Luckert, P. H.: Influence of isoflavones in soy protein isolates on development of induced prostate-related cancers in L-W rats. Nutr Cancer, 28: 41, 1997

10. Peterson, T. G. and Barnes, S.: Genistein and biochanin A inhibit the growth of human prostate cancer cells, but not epidermal growth factor receptor tyrosine auto-phosphorylation. Prostate, 22: 333, 1993

11. Barnes, S., Kirk, M. and Coward, L.: Isoflavones and their conjugates in soy foods: extraction conditions and analysis by HPLC-mass spectrometry. J Agric Food Chem, 42: 2466, 1994

12. Myers, R. B., Brown, D., Oelschlager, D. K. et al: Elevated serum levels of p105erbb-2 in patients with advanced stage prostatic adenocarcinoma. Int J Cancer (Pred Oncol), 69: 398, 1996

13. Synchron LX Systems Chemistry Information Manual. XXX.

14. Coward, L., Kirk, M., Albin, N. et al: Analysis of plasma isoflavones by reversed-phase hplc-multiple reaction ion monitoring-mass spectrometry. Clin Chim Acta, 247: 121, 1996

15. Barnes, S., Coward, L. and Kirk, M.: HPLC-mass spectrometry analysis of isoflavones. Proc Soc Exp Biol Med, 217: 254, 1998

16. Siegel, S. and Castellan, N. J.: Nonparametic Statistics for the Behavioral Sciences, 2nd ed. New York: McGraw-Hill, 1988

17. Anderson, J. W., Johnstone, B. M. and Cook-Newell, M. E.: Meta-analysis of the effects of soy protein intake on serum lipids. New Engl J Med, 333: 276, 1995

18. Crouse, J. R., III, Morgan, T., Terry, J. G. et al: A randomized trial comparing the effect of casein with that of soy protein containing varying amounts of isoflavones on plasma concentrations of lipids and lipoproteins. Arch Intern Med, 159: 2070, 1999 
19. Tyroler, H. A.: Total serum cholesterol and ischemic heart disease risk in clinical trials and observational studies. Am J Prevent Med, 1: 18, 1985

20. Kirk, E. A., Sutherland, P., Wang, S. A. et al: Isoflavones reduce plasma cholesterol and atherosclerosis in C57BL/6 mice but not LDL receptor-deficient mice. J Nutr, 128: 954, 1998

21. Sirtori, C. R., Gianazza, E., Manzoni, C. et al: Role of isoflavones in the cholesterol reduction by soy proteins in the clinic. Am J Clin Nutr, 65: 166, 1997

22. Tovar-Palacio, C., Potter, S. M., Hafermann, J. C. et al: Intake of soy protein and soy protein extracts influences lipid metabolism and hepatic gene expression in gerbils. J Nutr, 128: 839, 1998
23. Potter, S. M.: Soy protein and cardiovascular disease: the impact of bioactive components in soy. Nutr Rev, 56: 231, 1998

24. Onozawa, M., Fukuda, K., Ohtani, M. et al: Effects of soybean isoflavones on cell growth and apoptosis of the human prostatic cancer cell line LNCaP. Jpn J Clin Oncol, 28: 360, 1998

25. Zhou, J. R., Gugger, E. T., Tanaka, T. et al: Soybean phytochemicals inhibit the growth of transplantable human prostate carcinoma and tumor angiogenesis in mice. J Nutr, 129: 1628, 1999

26. Stephens, F. O.: Phytoestrogens and prostate cancer: possible preventive role. Med J Austr, 167: 138, 1997 